\title{
Dictionnaire François Mauriac, dir. C. CASSEVILLE et J. TOUzoT, Paris
}

\section{Michela Gardini}

\section{CpenEdition \\ Journals}

\section{Edizione digitale}

URL: https://journals.openedition.org/studifrancesi/23072

DOI: 10.4000/studifrancesi.23072

ISSN: 2421-5856

\section{Editore}

Rosenberg \& Sellier

\section{Edizione cartacea}

Data di pubblicazione: 1 avril 2020

Paginazione: 214

ISSN: 0039-2944

Notizia bibliografica digitale

Michela Gardini, «Dictionnaire François Mauriac, dir. C. casseville et J. touzot, Paris», Studi Francesi

[Online], 190 (LXIV | I) | 2020, online dal 01 mai 2020, consultato il 03 août 2021. URL: http://

journals.openedition.org/studifrancesi/23072 ; DOI: https://doi.org/10.4000/studifrancesi.23072

Questo documento è stato generato automaticamente il 3 août 2021.

\section{(c) (†)}

Studi Francesi è distribuita con Licenza Creative Commons Attribuzione - Non commerciale - Non opere derivate 4.0 Internazionale. 


\title{
Dictionnaire François Mauriac, dir. C. CASSEVILLE et J. TOUZOT, Paris
}

\author{
Michela Gardini
}

\section{NOTIZIA}

Dictionnaire François Mauriac, dir. C. CASSEVILLE et J. TOUZOT, Paris, Champion, 2019, 1205

pp.

1 Il monumentale Dictionnaire François Mauriac rappresenta un preziosissimo strumento di lavoro per tutti gli studiosi dello scrittore al quale, attraverso quest'opera, viene riconosciuto un ruolo centrale nel panorama della letteratura francese del Novecento, ruolo a lungo offuscato dal dominio intellettuale sartriano. Le voci, in totale settecento, affidate a settantadue contributori, costituiscono la chiave d'accesso indispensabile per orientarsi nella vastissima produzione che l'autore ci ha lasciato, tra romanzi, poesie, saggi, articoli, lettere. Se, da una parte, esse tratteggiano il contesto squisitamente novecentesco nel quale lo scrittore visse, dall'altra esse suscitano l'interesse del lettore del XXI secolo che scopre un autore inaspettatamente attuale, sensibile nel profondo alle questioni ambientali (voce «Écologie», pp. 387-388), persino post-ideologico ante litteram potremmo dire, refrattario al settarismo delle ideologie che, al contrario, caratterizzava ampiamente gli schieramenti letterari dei suoi contemporanei. «On le croit de droite, il pense à gauche», scrive Caroline CASSEVILLE nell'«Introduction» (p. 11), è cattolico, ma suscita la collera dei critici cattolici (si veda la voce «Critique catholique», pp. 312-315), è borghese ma smaschera le ipocrisie della morale borghese. $\mathrm{Ma}$, soprattutto, dedica ampia parte della sua riflessione alla giustizia, intesa come responsabilità morale e politica, oltre che religiosa. "Ce qu'il y a de plus horrible au monde, c'est la justice séparée de la charité», afferma Mauriac (voce «Justice», pp. 625-628), manifestando un'attenzione reale all'esercizio pratico della giustizia, dalla guerra d'Algeria alle liste nere degli scrittori collaborazionisti ai casi noti della cronaca nera, come quelli di Violette Nozière o delle sorelle Papin. Per Mauriac non 
bisognerebbe mai ridurre l'accusato all'atto criminale, a vantaggio di una giustizia «qui s'efforcerait de punir sans avilir, qui n'oublierait jamais qu'elle est donnée au nom d'une certaine dignité de l'homme» («Justice»). Nel discorso pronunciato all'Accademia di Stoccolma in occasione dell'attribuzione del premio Nobel nel 1952, viene messo l'accento sulla sua capacità di penetrare nell'animo umano («Prix Nobel», pp. 917-918). Intimamente legato al suo "piccolo mondo antico", Mauriac veicola, in realtà, con il talento letterario che il premio gli riconosce, valori ancestrali e universali che, proprio per questo, rendono lo scrittore un classico. Dalla voce «Abbayes et couvents» a «Zola», in ordine alfabetico il Dictionnaire assembla una pluralità di sguardi nel tentativo riuscito di compendiare l'universo di François Mauriac attraverso temi, luoghi, personaggi storici, scrittori, titoli di opere. Correda il volume un'utile «Bibliographie» comprendente gli studi critici dedicati allo scrittore. 